\title{
Avaliação laboratorial da estabilidade do padrão calibrador de bilirrubina
}

\author{
Laboratorial evaluation of standard bilirubin stability
}

\author{
Maria das Graças da Cunha Leite ${ }^{1}$ \\ Fernando Perazzini Facchini² \\ Eliana Cotta de Faria ${ }^{3}$ \\ Mirian Regina Gardin Danelon ${ }^{4}$
}

\section{unitermos resumo}

Bilirrubina

Introdução: O preparo do padrão calibrador de bilirrubina é essencial para um controle

Padrão calibrador

adequado das dosagens laboratoriais da bilirrubinemia, visto que estas estão sujeitas a grande

variabilidade nos resultados, dependendo do método de dosagem escolhido e da falta de

Icterícia

padronização rigorosa na sua execução. Uma vez preparado, este padrão calibrador deve ser

Hiperbilirrubinemia

dividido em alíquotas e estocado para ser utilizado de rotina. Objetivo: Avaliar os efeitos de

diferentes condições de armazenamento de um padrão calibrador de bilirrubina sobre sua

estabilidade, com finalidade de calibração de equipamentos utilizados na determinação da

bilirrubinemia em neonatos. Material e métodos: Após o preparo de um padrão calibrador

com $25 \mathrm{mg} / \mathrm{dl}$ de bilirrubina, este foi armazenado a $4^{\circ} \mathrm{C}$, congelado a $-20^{\circ} \mathrm{C}$ e a $-70^{\circ} \mathrm{C}$.

Durante nove meses foram feitas dosagens consecutivas da bilirrubina da solução padrão,

as quais foram analisadas através da análise de variância de duas vias com blocagem.

Resultados: As amostras congeladas a $-70^{\circ} \mathrm{C}$ não sofreram degradação significativa nos

nove meses estudados, enquanto que, no período de três meses, as congeladas a $-20^{\circ} \mathrm{C}$

e a $4^{\circ} \mathrm{C}$ sofreram uma degradação de $5 \%$ e $24,18 \%$, respectivamente, dos níveis iniciais

de bilirrubina. Conclusão: A estocagem do padrão calibrador de bilirrubina a $-70^{\circ} \mathrm{C}$ é a

recomendada para a preservação dos níveis de bilirrubina.

\section{abstract}

Background: The preparation of a standard bilirubin is essential for an adequate quality control of laboratorial bilirubinemia measurements because they are subjected to a large variability in results depending on the dosage method used and the lack of a rigorous standardization of its performance. Once prepared, this standard solution has to be divided in aliquots and stored to be routinely used. Objective: To evaluate the effect of different conditions of the standard solution storage in the stability of bilirubin with the purpose of using it for calibration of equipment used in the dosage of bilirubin in neonates. M ethods: After the preparation of standard solution with $25 \mathrm{mg} / \mathrm{dl}$ of bilirubin, it was stored under $4^{\circ} \mathrm{C}$ or frozen under $-20^{\circ} \mathrm{C}$ and $-70^{\circ} \mathrm{C}$. During the next nine months, consecutive bilirubin dosages of the standard solution were performed and the results analyzed through the Anova-two-ways. Results: The samples frozen under $-70^{\circ} \mathrm{C}$ did not present a significant degradation during nine months, while those under $-20^{\circ} \mathrm{C}$ and $4{ }^{\circ} \mathrm{C}$ suffered

a degradation of $5 \%$ and $24,18 \%$ of bilirubin levels, respectively, during the period of three months. Conclusion: Storage of standard bilirubin solution under $-70^{\circ} \mathrm{C}$ is recommended for the maintenance of constant bilirubin concentration.

\section{key words}

Bilirubin

Bilirubin standard

Jaundice

Hyperbilirubinemia

Campinas (FCM/Unicamp)

2. Professor doutor do

Departamento de Pediatria da

FCM/Unicamp.

3. Professora doutora do Departamento de Patologia

Clínica da FCM/Unicamp

4. Bióloga do Serviço de Bioquímica

Clínica do Hospital das Clínicas

da Unicamp.

Trabalho realizado na Divisão de Neonatologia do Centro

de Assistência Integral à Saúde da Mulher (Caism/Unicamp) e

Laboratóriode Patologia Clínica do Hospital das Clínicas da Unicamp

Financiado pela Fundação de

Amparo à Pesquisa do Estado

de São Paulo (Fafesp) -

processo 00/03909-0.

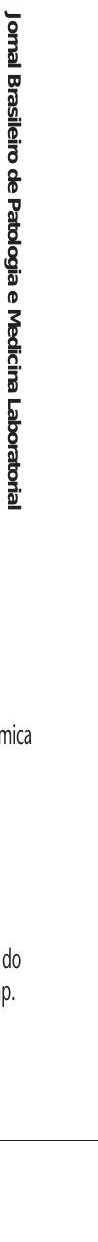




\section{Introdução}

A dosagem de bilirrubinemia é um dos exames laboratoriais mais utilizados nos primeiros dias de vida e por isso mesmo de fundamental importância para os neonatologistas. Um exame confiável evita coletas de sangue desnecessárias, custos aumentados e tratamentos dispensáveis, alguns inclusive de alto risco para os pacientes.

A qualidade de qualquer análise bioquímica depende da metodologia empregada e de um adequado controle de qualidade rotineiramente usado no laboratório.

Embora fartamente usadas, as dosagens laboratoriais da bilirrubinemia estão sujeitas a grande variabilidade, dependendo do método escolhido e da padronização de sua execução $(2,12,16)$.

Em 1960, Mather (8) já afirmava: "A determinação da bilirrubina é a mais irreal das dosagens bioquímicas". O uso de padrões inadequados é citado como a principal causa da variabilidade dos resultados (3).

Entre 1968 e 1971, o Colégio Americano de Patologistas documentou os problemas associados à determinação de bilirrubinemia com a participação de 1.500 laboratórios que mediram a bilirrubinemia total em amostras padronizadas com concentração idêntica de bilirrubina, encontrando um coeficiente de variação entre 10,1\% e 15,3\% (3). Isto quer dizer que, se a bilirrubina sérica é na verdade de $20 \mathrm{mg} / \mathrm{dl}$, um coeficiente de variação de $10 \%$ entre laboratórios significa que a duplicação de uma análise pode resultar em qualquer valor entre $16 \mathrm{mg} / \mathrm{dl}$ e $24 \mathrm{mg} / \mathrm{dl}$. Em 1982, uma pesquisa em 67 laboratórios no estado de Indiana, EUA, documentou valores de bilirrubinemia de $10,9 \mathrm{mg} / \mathrm{dl}$ a $24 \mathrm{mg} / \mathrm{dl}$ para um soro com uma concentração média conhecida de $18,1 \mathrm{mg} / \mathrm{dl}$ de bilirrubina total (8). No mesmo ano, Watkinson e St. John Penberthy (17) também encontraram uma ampla variação interlaboratorial na Austrália e Nova Zelândia.

Para um controle de qualidade analítico adequado, o uso de padrões de calibração de bilirrubina é essencial. Desde 1962, um comitê composto por representantes da American Academy of Pediatrics, College of American Pathologists, American Association of Clinical Chemists e National Institute of Health recomendou o preparo de uma solução-padrão de bilirrubina visando a uniformizar as dosagens laboratoriais (6).

Recomenda-se, antes do preparo deste padrão calibrador, a análise de pureza do sal de bilirrubina através da sua absortividade molar em clorofórmio. Como matriz protéica da solução padrão podem ser usados plas- ma humano ou albumina humana ou bovina. O plasma é preferível por apresentar uma absorvância ideal independente do método usado. Esta solução pode ser preparada com boa reprodutibilidade (coeficiente de variação menor que $0,5 \%$ ) se forem seguidos rigorosamente os procedimentos necessários para o seu preparo (3).

Uma vez preparado o padrão calibrador, este deve ser convenientemente dividido em alíquotas e armazenado, a fim de que possa ser usado rotineiramente. Uma questão polêmica na literatura mundial $(3,6,13)$ é a maneira ideal para a sua estocagem.

\section{Objetivo}

O objetivo deste estudo foi avaliar os efeitos de diferentes condições de armazenamento de um padrão calibrador de bilirrubina sobre sua estabilidade, com a finalidade de calibração de equipamentos utilizados na determinação da bilirrubinemia em neonatos.

\section{Materiais e métodos}

\section{Preparo da solução padrão de bilirrubina}

O sangue de cordão umbilical para obtenção do pool de plasma foi obtido no centro obstétrico do Centro de Assistência Integral à Saúde da Mulher, da Universidade de Campinas (Caism/Unicamp). Foram preparadas cinco bolsas de coleta de sangue contendo $9 \mathrm{ml}$ de anticoagulante CPDA e completadas para $80 \mathrm{ml}$ cada uma com sangue de cordão logo após o parto. Após centrifugação a 2.500rpm, separou-se o pool de plasma fresco.

O padrão calibrador de bilirrubina foi preparado no Serviço de Bioquímica Clínica da Divisão de Patologia Clínica, Hospital das Clínicas, Unicamp, a partir do sal Bilirrubina Mixed Isomers da Sigma - Código B-4126 Lote $117 \mathrm{H} 12831$, armazenado em frasco âmbar, protegido da luz e mantido a $-70^{\circ} \mathrm{C}(6)$.

O grau de pureza do sal foi analisado com uma solução de concentração de $0,005 \mathrm{~g} / \mathrm{l}$ em espectrofotômetro Spectronic genesys 5, comprimento de onda $453 \mathrm{~nm}$, a $25^{\circ} \mathrm{C}$, obtendo-se o valor de $92,73 \%$.

Preparo da solução padrão de bilirrubina a $25 \mathrm{mg} / \mathrm{dl}$ : pesou-se, em balança analítica de precisão Mettler H35 AR, $0,027 g$ de bilirrubina $(25 g+1,8125 g$ de impureza) e dissolveu-se com $1 \mathrm{ml}$ de dimetil sulfóxido (DMSO) e $2 \mathrm{ml}$ de $\mathrm{Na}_{2} \mathrm{CO}_{3}$ 0,1 $\mathrm{mol} / \mathrm{l}$. Foram então adicionados $2 \mathrm{ml}$ de $\mathrm{HCL} 0,1 \mathrm{~mol} / \mathrm{l}$ e o volume final de $100 \mathrm{ml}$ foi completado 
com o plasma. Antes, ajustou-se o $\mathrm{pH}$ de $100 \mathrm{ml}$ de plasma de cordão umbilical para 7,35 com $\mathrm{NaOH} 0,1 \mathrm{~N}$ e a concentração de albumina para $3,8 \mathrm{~g} / \mathrm{dl}$ com a adição de $2,1 \mathrm{~g}$ de albumina bovina.

\section{Dosagem da solução padrão de bilirrubina}

A bilirrubina total foi quantificada pelo método colorimétrico Jendrassik-Gröf (5) em sistema de automação Hitachi 917 (Roche), obtendo-se os seguintes resultados $(\mathrm{em} \mathrm{mg} / \mathrm{dl}): 23,9 \pm 0,11$; coeficiente de variação $(\mathrm{CV})=$ $0,44 \%,(n=10)$.

O resultado obtido para uso do padrão foi de $23,7 \mathrm{mg} / \mathrm{dl}$ a 24,1 mg/dl (média \pm 2 SD).

No Setor de Neonatologia do Caism/Unicamp, foi feita a valoração do padrão calibrador através da espectrofotometria direta utilizando-se o Bilirrubinômetro Unistat Modelo 10310C/10311C - Leica.

Obtiveram-se os seguintes resultados (em mg/dl): 25,9 $\pm 0,98$; coeficiente de variação $=3,78 \%(n=15)$; intervalo interpercentis $2,5 \%$ e $97,5 \%=24,9 \mathrm{mg} / \mathrm{dl}$ a $26,9 \mathrm{mg} / \mathrm{dl}$. Este coeficiente de variação obtido é perfeitamente aceitável, pois, de acordo com o fabricante do bilirrubinômetro, o aparelho pode apresentar um CV de até 5\% (15).

Após as dosagens, as alíquotas do padrão foram armazenadas em três diferentes condições para avaliação da estabilidade : 1) refrigeradas a $4{ }^{\circ} \mathrm{C} ; 2$ ) congeladas a $-20^{\circ} \mathrm{C}$; 3) congeladas a $-70^{\circ} \mathrm{C}$.

Durante um período de nove meses, foram feitas dosagens consecutivas das diferentes formas de armazenamentos das amostras no Bilirrubinômetro Unistat para avaliarmos a possível degradação da bilirrubina no soro.

As amostras congeladas a $-70^{\circ} \mathrm{C}$ foram dosadas uma vez por mês nos três primeiros meses e novamente com nove meses de armazenamento. As congeladas a $-20^{\circ} \mathrm{C}$ foram dosadas de 15 em 15 dias, durante três meses. Já as refrigeradas foram dosadas diariamente por um período de dez dias. Cada amostra padrão foi dosada quatro vezes, sendo usados cinco frascos de amostras padrão por dia, obtendo-se um total de 20 dosagens ao dia.

O método estatístico usado para avaliação dos resultados foi a análise de variância (Anova) de duas vias com blocagem (10).

\section{Resultados}

Nos três grupos não foi encontrada variação referente aos frascos.
As três tabelas abaixo mostram os resultados dos testes de armazenamento a $4^{\circ} \mathrm{C},-20^{\circ} \mathrm{C} \mathrm{e}-70^{\circ} \mathrm{C}$.

Considerando-se a variabilidade causada pelo fator tempo, é possível observar nítida degradação da bilirrubina após dez dias de refrigeração a $4^{\circ} \mathrm{C}$ (Tabela 1 ). A queda foi de $24,18 \%$.

Considerando-se ainda a variabilidade causada pelo fator tempo, demonstrou-se também haver diferença estatisticamente significativa entre as dosagens neste grupo após três meses de congelamento a $-20^{\circ} \mathrm{C}$, sendo que a queda foi de $5 \%$ neste período (Tabela 2).

Não houve variabilidade significativa em função do tempo, demonstrando-se não haver diferenças nas amostras congeladas a $-70^{\circ} \mathrm{C}$ após nove meses, ou seja, o padrão calibrador manteve-se estável e válido para uso (Tabela 3).

\begin{tabular}{cccc} 
& \multicolumn{3}{c}{$\begin{array}{l}\text { Teste da estabilidade do padrão } \\
\text { Tabela 1 }\end{array}$} \\
calibrador de bilirrubina a $\mathbf{4}^{\circ} \mathbf{C}$
\end{tabular}

Anova entre ensaios: $p=0,5$; entre tempos: $p<0,0001 ; n=$ número de dosagens.

Teste da estabilidade do padrão Tabela 2 calibrador de bilirrubina a - $20^{\circ} \mathrm{C}$

$\begin{array}{cccc}\text { Tempo (quinzenas) } & \text { n } & \text { Média }(\mathrm{mg} / \mathrm{dl}) & \text { Desvio padrão } \\ 0 & 15 & 25,88 & 0,49 \\ 1 & 20 & 24,32 & 1,03 \\ 2 & 20 & 25,2 & 1,15 \\ 3 & 20 & 25,31 & 1,03 \\ 4 & 20 & 25,18 & 0,6 \\ 5 & 20 & 24,46 & 0,63 \\ 6 & 20 & 24,57 & 0,37\end{array}$

Anova entre ensaios: $p=0,93$; entre tempos: $p<0,0001 ; n=$ número de dosagens. 


\begin{tabular}{cccc} 
Tabela 3 & \multicolumn{3}{c|}{$\begin{array}{c}\text { Teste da estabilidade do padrão } \\
\text { calibrador de bilirrubina a }-\mathbf{7 0}^{\circ} \mathbf{C}\end{array}$} \\
\hline Tempo (meses) & $n$ & Média (mg/ dl) & Desvio padrão \\
\hline 0 & 15 & 25,88 & 0,49 \\
1 & 20 & 25,8 & 0,72 \\
2 & 20 & 25,66 & 0,36 \\
3 & 20 & 25,86 & 0,27 \\
9 & 20 & 25,45 & 0,56 \\
\hline
\end{tabular}

Anova entre ensaios: $p=0,27$; entre tempos: $p=0,48 ; n=$ número de dosagens.

\section{Discussão}

É descrito na literatura que o uso de padrões preparados artesanalmente é preferível ao uso de padrões comerciais liofilizados, pois foi demonstrado que estes últimos, se utilizados em espectrofotometria direta, podem conter substâncias formadas após reconstituição que diminuem os valores apurados de bilirrubina em até $18 \%$ (1). Estas substâncias seriam produto de desnaturação de lipoproteínas que causariam turvação do soro, atrapalhando a absortividade da bilirrubina (2).

No preparo da solução padrão de bilirrubina, optamos por usar plasma de cordão umbilical por não conter pigmentos que possam ser lidos juntamente com a bilirrubina devido à semelhança na absorção da luz, como é o caso do caroteno.

A estabilidade da solução padrão de bilirrubina não tem sido conclusivamente estabelecida. Não há um consenso sobre a forma de armazenamento do soro padrão, existindo relatos de adequada conservação a $-20^{\circ} \mathrm{C}$ durante uma semana (6), por dez meses (13) e até indefinidamente (14). Por outro lado, Dybkaer e Hertz (4) e Rand e Pasqua (11) demonstraram que nesta estocagem ela se manteve estável por cerca de um mês apenas.
Doumas et al. (3) estudaram a estabilidade da solução padrão preparada com albumina bovina, demonstrando que, a $-23^{\circ} \mathrm{C}$, um padrão de $20 \mathrm{mg} / \mathrm{dl}$ se deteriorou $2 \%$ ao mês quando era preparado na concentração de $4 \mathrm{~g} / \mathrm{dl}$ de albumina e 1,5\% ao mês quando era preparado com $8 \mathrm{~g} / \mathrm{dl}$ de albumina. O mesmo estudo analisou soluções padrão de bilirrubina preparadas tanto com pool de plasma, quanto com albumina humana e albumina bovina, estocadas a $-70^{\circ} \mathrm{C}$, onde não foi evidenciada deterioração significativa num período de sete meses. Demonstraram ainda que, quando estocada a $-16^{\circ} \mathrm{C}$, houve deterioração de $4 \%$ num período de 12 dias.

Em 1990, Sykes e Epstein (15) relataram que a bilirrubina é estável a $4^{\circ} \mathrm{C}$ por três dias e a $-70^{\circ} \mathrm{C}$ por três meses.

Em nosso estudo, os diferentes tempos escolhidos para a análise da degradação da bilirrubina foram baseados nas informações previamente obtidas pela literatura, onde sabidamente a refrigeração apresenta rápida degradação da bilirrubina, o congelamento a $-20^{\circ} \mathrm{C}$ degradaria mais lentamente e a $-70^{\circ} \mathrm{C}$ seria quase imperceptível em períodos curtos. $\mathrm{O}$ congelamento a $-20^{\circ} \mathrm{C}$ é o meio mais acessível para a maioria das instituições, mas como houve degradação de $5 \%$ em três meses, recomendamos cautela para o seu uso. Apenas a $-70^{\circ} \mathrm{C}$ houve preservação dos valores das dosagens durante o período de nove meses. Estes resultados estão de acordo com o descrito na literatura, mas ainda não se sabe qual o tempo máximo que a solução padrão se mantém estável nestas condições.

\section{Conclusão}

Recomendamos, portanto, que o padrão calibrador preparado nas condições experimentais descritas seja armazenado a $-70^{\circ} \mathrm{C}$ para uso de rotina diário em equipamentos usados para a determinação da bilirrubinemia em neonatos.

\section{Referências}

1. A menta, J.S. \& Silverman, J.A. Commercially prepared bilirubin standards may not be valid for use with direct spectrophotometric assay. Clin. Chem., 28(8): 1812, 1982

2. Doumas, B.T. \& Eckfeldt, J.H. Errors in measurement of total bilirubin: a perennial problem. Clin. Chem., 42: 845-8, 1996.

3. D o umas, B.T. et al. Standardization in bilirubin assays: Evaluation of selected methods and stability of bilirubin solutions. Clin. Chem., 19(9): 984-93, 1973.

4.Dybkaer,R.\& Hertz,H . A reference for determination of bilirubin concentration in serum using bilirubin in cyanide-formamide for enrichment of serum. Scand. J. Clin. Lab. Invest. 25: 151-4, 1970.

5. Jendrassik, L. \& Grof, P. Vereinfachte photometrische methoden zur bestimmung des blutbilirubins. Biochem Z,297:81-9,1938.

6. Joint Committee Report. Recommendation on a uniform bilirubin standard. Clin. Chem., 8: 405-7, 1962.

7. Leica 0 ptical Systems Division. Instruction Manual - 10310C/ 10311C . Unistat Bilirubinometer. Buffalo: Leica Inc., 1992. 
8. Maisels, M. J. Icterícia. In: A very, G.B., Fletcher, M.A., Mac D onald, M.G . (eds.) N eonatologia: fisiopatologia e tratamento do recém-nascido. 4a ed. Belo Horizonte: Medsi, 1999. p. 686.

9. Mather, A. Reliability of bilirubin determinations in icterus of the newborn infant. Pediatrics, 26:350-4, 1960.

10. Montgomery, D.C. Design and analysis of experiments. $3^{\text {th }}$ ed. W iley: Courier Companies, 1991.

11. Rand, R.N. \& Pasqua, A. A new diazo method for the determination of bilirubin. Clin. Chem., 8: 570-6, 1962

12. Rosenthal, P. Errors in neonatal bilirubin measurement. Clin. Chem., 42(11): 1880-1, 1996.
13. Simmons, N.A. An automated method for serum bilirubin determination. J. Clin. Pathol., 21: 196-201, 1968 .

14. Sims, F.H \& \& Horn, C. Some observations on Powell's method for the determination of serum bilirubin. Amer.J. Clin. Pathol, 29:412-8, 1958.

15. Sykes, E. \& Epstein, E. Laboratory measurement of bilirubin. Clin. Perinatol.,17(2): 397-416, 1990.

16. Vreman, $\mathrm{H}$.J. et al. Interlaboratory variability of bilirubin measurements. Clin. Chem., 42: 869-73, 1996.

17. W atkinson, L.R. \& St. John Penberthy, L. A. Investigation into pediatric bilirubin analyses in Australia and $\mathrm{N}$ ew Zealand. J. Clin. Pathol., 35: 52-8, 1982. 